\title{
EFFECT OF EURYCOMA LONGIFOLIA ON SEXUAL BEHAVIOR IN SEXUALLY DYSFUNCTIONAL MALE: A SYSTEMATIC REVIEW
}

\author{
PUTRI AYU JAYUSMAN, ISA NAINA MOHAMED, HNIN EI THU, AHMAD NAZRUN SHUID* \\ Department of Pharmacology, Faculty of Medicine, Universiti Kebangsaan Malaysia, Jalan Yaacob Latif, 56000 Cheras, Kuala Lumpur, \\ Malaysia \\ Email: anazrun@yahoo.com
}

Received: 04 Aug 2017 Revised and Accepted: 02 Nov 2017

\begin{abstract}
Objective: This systematic review was conducted to summarize and evaluate the effect of Eurycoma longifolia (EL) on sexual behavior in the sexually dysfunctional male.

Methods: Ovid Medline, Wiley Online Library, Scopus, BioMed Central, Hindawi and Google Scholar databases were searched for relevant studies published from 1995 to 2016 and search was limited to relevant studies published in English. Studies assessing aphrodisiac properties of EL on male sexual behavior in sexually dysfunctional animal models or human were included.
\end{abstract}

Results: Among the 155 studies identified in the literature search, a total of 6 eligible articles (5 animal studies and one human study) were selected and reviewed. All studies reported positive aphrodisiac activities and supported the use of the plant as an aphrodisiac.

Conclusion: This systematic review highlighted the effect of EL extract as an aphrodisiac agent to improve sexual behavior in the sexually dysfunctional male. Further studies are required to determine the specific mechanisms of action and identification of the bioactive components of EL responsible for its potential efficacy.

Keywords: E. longifolia, Tongkat ali, Aphrodisiac, Sexual behaviour, Sexual dysfunction

(C) 2017 The Authors. Published by Innovare Academic Sciences Pvt Ltd. This is an open-access article under the CC BY license (http://creativecommons.org/licenses/by/4.0/) DOI: http://dx.doi.org/10.22159/ijpps.2017v9i12.21812

\section{INTRODUCTION}

Libido, erection, orgasm, ejaculation and detumescence are five interrelated events that must occur in a defined sequence for a normal male sexual response cycle. Any disturbance in the effective performance/completion of this sexual response cycle or disruption of the sequence order is defined as male sexual dysfunction [1]. The prevalence increases as men age, in which approximately $20-30 \%$ of adult men manifest at least one sexual dysfunction [2]. Male sexual dysfunction includes premature ejaculation, retrograded, retarded or inhibited ejaculation, erectile dysfunction, arousal difficulties (reduced libido), compulsive sexual behaviour, orgasmic disorder and failure of detumescence [3].

Erectile dysfunction (ED) or impotence and premature ejaculation (PE) were reported to be the two most prevalent sexual dysfunction complaints in male sexual medicine [4]. Dissatisfaction in males' sexual well-being is significantly caused by ED which is characterized by persistent inability to attain and maintain an erection that is sufficient to permit satisfactory sexual performance [5]. Studies have found that ED occurs commonly in middle-aged and older men. Age-dependent increases of ED' prevalence from age group 30 to $80 \mathrm{y}$ was reported in a study by Braun, Wassmer [6]. Etiology of ED was reported to be mainly due to chronic diseases such as diabetes mellitus and atherosclerosis [7]. Endocrine disorder like low testosterone and thyroid problems also contributes to ED [8].

Meanwhile, according to the Second International Consultation on Sexual and Erectile Dysfunction, PE was defined as ejaculation with minimal stimulation and earlier than desired, before or soon after penetration which the sufferer has little or no voluntary control [9]. In contrast to ED, the prevalence of PE is not affected by age [10] in which the risk factors are generally unknown. The cases of PE correlates significantly with ED, about one-third of PE patients may have complaint for ED [11]. Despite having been successfully treated for ED, some patients remained sexually frustrated by PE [12].

Treatment of sexual dysfunction is important for any couple seeking for fertility [13]. Proper sexual functioning is also a crucial component of maintaining a satisfying intimate relationship and self-esteem [8]. However, due to taboos and cultural restrictions, most Asian men do not seek for medical treatment [14]. Despite the importance and high prevalence of sexual dysfunctions, most sufferers do not view it as a medical problem besides the feeling of embarrassment [15].

Several medical therapies for the treatments of male sexual dysfunction remain unsatisfactory due to its invasiveness. For instance, intracavernosal injection therapy is effective for the treatment of ED, but it is invasive and associated with a high rate of withdrawal from treatment [16]. Sildenafil is the first-line oral therapy that is effective for the treatment of ED. Though effective in circumventing the cause of ED, oral sildenafil therapy provides only short-term symptomatic relief of the condition [17]. The Asian MALES study has revealed that a majority or near majority of Asian men with self-reported ED have never sought treatment [18]. Meanwhile, testosterone replacement therapy is the treatment option for hormonal causes of ED. Although this therapy may benefits men with hypogonadism, issues regarding its potential risks and side effects such as cardiovascular disease, prostate cancer and hepatotoxicity remain controversial [19]. A study reported that almost $35 \%$ of hypogonadal men did not receive testosterone therapy due to fear of prostate cancer risk [20].

Considering the pros and cons of available modern treatment, alternative herbal remedies with a long history of traditional usage have been popularly sought after and known worldwide as an "instant" treatment for sexual inadequacies [21]. It was also not uncommon for Asian men to consider traditional herbal medicine as an alternative to improve their sexual well-being [18]. The increased incidence of male sexual dysfunction has leads to more and rapid scientific search into plants with aphrodisiac potential [22]. An aphrodisiac can be described as any substances that were used to treat a sexual disorder or to enhance sexual behaviour and satisfaction in humans and animals. It acts primarily by altering the level of specific neurotransmitters or specific sex hormone into the 
body, i. e alteration in testosterone level [23]. Several in vivo and in vitro models have been established for the determination of aphrodisiac activity [22].

Eurycoma longifolia (EL) was reported to have a potential effect on the sexual functions supporting the folk claims and uses as an aphrodisiac. It was reputed to be a cure for symptoms of impotence, loss of desire/libido and improved testosterone production [24-25]. This plant is popularly known as "Tongkat Ali" which was assigned due to the presence of long twisted roots. The root of this plant, which is the most valuable component, is being boiled and consumed traditionally as a tonic for aphrodisiac effects and energy [26]. Regular intake of the root extracts is believed to enhance testosterone levels in men.

The phytoandrogenic properties of EL suggested its clinical application as a natural alternative to testosterone replacement therapy. Apart from its aphrodisiac effects, the roots have been used to treat a wide range of ailments including fever, malaria, migraine and arthritis. Nowadays, medicinal herbs that possess more than one chemical entity have been extensively hunt for research purposes [27]. The active components that are responsible for the reported benefits in EL extracts include quassinoids (eurycomanone), canthine-6-one alkaloids, squalene derivatives and by-phenylneolignans [28]. The quassinoid compound eurycomanone is used as a marker in a standardized water extract of EL [29] and this compound is reported to be responsible for the testosteroneenhancing effect. Aside from that, a bioactive peptide compound labeled as eurypeptides was also reported earlier to increase testosterone levels, sperm count and motility in animal models [30].

Since years ago, various researchers from animal studies to several human supplementation studies have been conducted to qualify the traditional claim of EL as an aphrodisiac agent. The present systematic review was therefore aimed at evaluating the effect of EL extract on sexual behaviour in sexually dysfunctional male, with a view to validate the use of the plant as an aphrodisiac in the folklore medicine.

\section{MATERIALS AND METHODS}

\section{Methods}

\section{Literature review}

A systematic review of the literature was conducted to investigate relevant studies relating to the effects of EL on sexual behaviour in the sexually dysfunctional male. Electronic bibliographic databases including Medline via Ovid, Scopus, Wiley Online Library, BioMed Central, Hindawi and Google Scholar were searched for a combination of the following two sets of keywords (1) Eurycoma longifolia OR tongkat ali AND (2) aphrodisiac OR male sexual health OR sexual behavior OR sexual motivation OR testosterone.

\section{Inclusion and exclusion criteria}

Articles were included if they fulfilled the following criteria: (1) the study assessed the aphrodisiac properties of EL extracts (2) sexual behaviour parameters were measured in sexually dysfunctional male subjects/animals (3) it was an original full article; (4) published in the English language. Articles were excluded from the review if: (1) it was a review article, case reports or letters to the editor (2) the study was using normal or healthy male subjects/animals (3) the study was presented as abstract only.

\section{Data extraction}

Articles published from 1995 to 2016 were selected. Research papers that did not match the inclusion criteria based solely on the titles and abstracts were excluded. The full-text articles were read thoroughly to exclude any paper that did not meet our inclusion criteria. In the case of duplicate publications, the most updated version was included in the review. The data of interest were extracted and the following data were recorded from the studies: (1) type of the study, (2) a brief description of the subject/sample, (3) type of EL extraction used, (4) methods used in the study, (5) a brief description of the results, (6) conclusion of the study. In order to determine the potential aphrodisiac activity of EL in the management of male sexual dysfunction, several principle parameters including sexual behaviour parameter (mounting and intromission frequency, mount, intromission, and ejaculatory latency and post-ejaculatory interval) and biochemical parameter (hormonal determination) were assessed.

\section{Review method}

All potential articles were identified and screened by three independent reviewers (P. A. J, A. N. S, I. N. M). Study selection and data extraction were performed following detailed discussion with all reviewers (P. A. J, H. E. T, A. N. S, I. N. M). Any disagreement or uncertainty about study inclusion was resolved by discussion with third and fourth reviewers (A. N. S, I. N. M).

\section{RESULTS}

\section{Search results}

An initial search of the electronic databases identified 155 articles. A total of 100 articles were excluded since they were not researching articles, not in English, not relevant to the objectives and focused on women sexual health. By screening the titles and abstracts of the articles left, 55 articles were further removed after found to be unrelated to the objective; they were in vitro studies or did not meet inclusion criteria.

Of the remaining 43 articles, the full-text of 5 articles failed to be retrieved. Upon careful scrutiny of the available full-texts, 32 articles were found to be unsatisfactory and discarded. Finally, only 6 articles remained to be included in this review. A flow diagram of the literature selection including reasons for exclusion is shown in fig. 1.

\section{Study characteristics}

Among the 6 included studies, 5 were in vivo animal study and one was a human study. The summary of the characteristics of the studies is displayed in table 1 . All animal studies used rats as the experimental model except for one study that used mice. The human study involved patients with late-onset hypogonadism (LOH). All studies were conducted based on an experimental design which compared the effect of EL treated groups with control or placebo group. Only one study by Ang, Cheang [31] included a positive control that was given testosterone for comparison. Methanol, chloroform, aqeous and butanol extracts of EL were used for the animal studies, while standardised hot water extract of EL was used for the human study.

In the animal studies on sexual behavior, the criteria for sexually dysfunction rats were either sexually sluggish or impotent, sexually naïve or non-copulator male rats. The sexually receptive female animal was used in the animal studies to evaluate the sexual behavior of tested males. One study by Ang, Cheang [31] used sexually inexperienced rats which were castrated by removing their testicles and epidydimal tissues. In another study, sexually naïve male mice were used as an experimental animal [32].

Sexual performance, libido, motivation or sexual qualities were evaluated through copulatory behavior. Zanoli, Zavatti [33] assessed mounting, intromission and ejaculation latency in copulatory behavior test while partner preference test was used to assess sexual motivation in sexually sluggish and impotent male rats. Ang and Sim [35] measured copulation activities, successful crossover and subsequent mountings in sexually naïve male rats. Copulatory behavior was also measured by choice selection and hesitation time in sexually sluggish male rats [34]. The sexual motivation of sexually naïve male mice was evaluated by the choice selection (choice: estrous female vs active male) using modified runway-choice and modified open field method in a study by Ang, Chan [32]. Meanwhile, Ang, Cheang [31] assessed sexual performance by measuring the cumulative percentage of castrated male rats responding to mounting, intromission and ejaculation. 
155 of studies identified through the search of electronic databases:

Medline via Ovid, Scopus, Wiley Online Library, Bio Med Central, Hindawi and Google Scholar

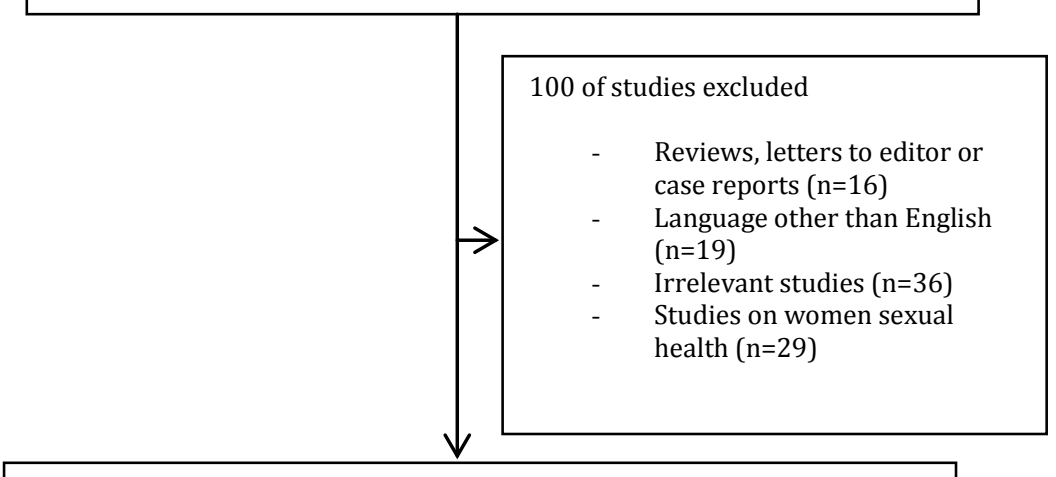

55 of studies screened on the basis of title and abstract

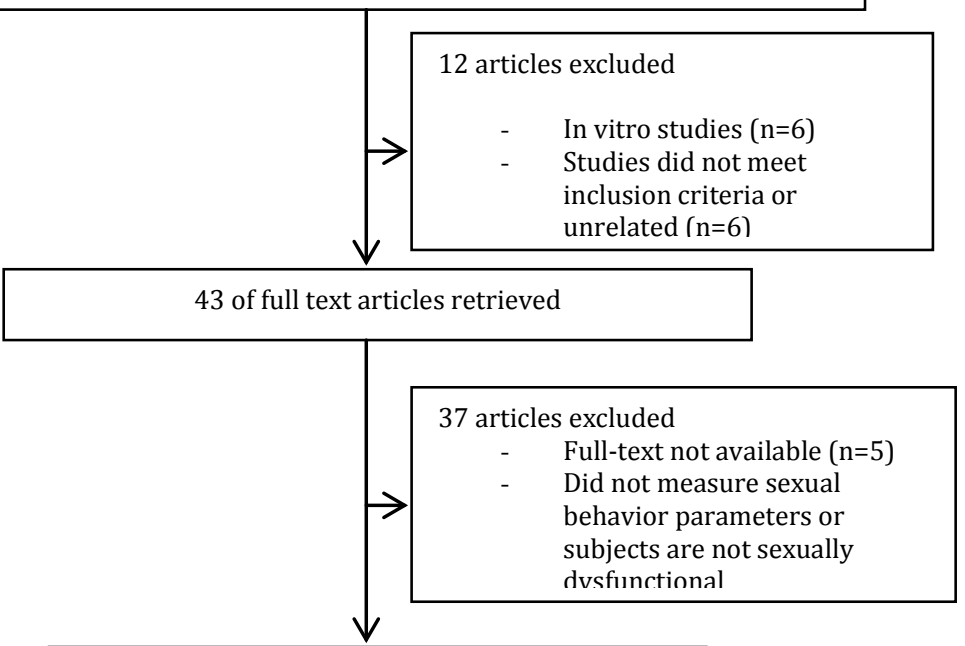

6 studies included in the review

Fig. 1: Flowchart to show the selection process of the articles in the review

Table 1: Characteristic of studies included in this review

\begin{tabular}{|c|c|c|c|c|c|c|c|}
\hline $\begin{array}{l}\text { Author } \\
\text { (y) }\end{array}$ & $\begin{array}{l}\text { Type of } \\
\text { study }\end{array}$ & $\begin{array}{l}\text { Test animal/ } \\
\text { sample }\end{array}$ & $\begin{array}{l}\text { Type of EL } \\
\text { extract }\end{array}$ & Dose & Methodology & Results & Conclusion \\
\hline $\begin{array}{l}\text { Zanoli, } \\
\text { Zavatti } \\
{[33]}\end{array}$ & $\begin{array}{l}\text { In vivo } \\
\text { animal } \\
\text { study. } \\
\text { Aphrodisiac } \\
\text { evaluation. }\end{array}$ & $\begin{array}{l}\text { Sexually } \\
\text { sluggish adult } \\
\text { male } \\
\text { Sprague- } \\
\text { dawley rats. }\end{array}$ & $\begin{array}{l}\text { Chlorofor } \\
\text { m, } \\
\text { methanol, } \\
\text { water, } \\
\text { butanol } \\
\text { extract }\end{array}$ & $\begin{array}{l}\text { Acute: } 250 \text {, } \\
500,1000 \\
\mathrm{mg} / \mathrm{kg} ; \\
\text { Subacute: } \\
500 \mathrm{mg} / \mathrm{kg} \\
\text { daily for } 6 \mathrm{~d} \text {; } \\
\text { Sub chronic: } \\
500 \mathrm{mg} / \mathrm{kg} \\
\text { daily dose for } \\
12 \mathrm{~d} .\end{array}$ & $\begin{array}{l}\text { - Rats were trained with } \\
\text { sexually receptive females } \\
\text { to classify males as } \\
\text { sexually potent, sluggish } \\
\text { or impotent. } \\
\text { - Sexual behaviour } \\
\text { parameters: } \\
\text { - Mount latency (ML), } \\
\text { percentage of mounting } \\
\text { (\%M), intromission } \\
\text { latency (IL), percentage of } \\
\text { ejaculation (\%E), } \\
\text { ejaculation latency (El) } \\
\text { and post-ejaculatory } \\
\text { interval (PEI) } \\
\text { - Partner preference } \\
\text { test-to evaluate sexual } \\
\text { motivation expressed by a } \\
\text { preference score. } \\
\text { - Testosterone assays- } \\
\text { Rats were divided into } \\
\text { two groups, control group }\end{array}$ & $\begin{array}{l}\text { - Significantly } \\
\text { reduced IL, increased } \\
\% \mathrm{M} \text { and reduced PEI } \\
\text { in sexually sluggish } \\
\text { rats receiving acute } \\
\text { (500 and } 1000 \\
\text { mg/kg) and subacute } \\
\text { treatment. } \\
\text { - Increased \%M and } \\
\% \text { E in impotent rats } \\
\text { (subacute and sub } \\
\text { chronic EL doses). } \\
\text { - Motivational } \\
\text { behavior of sluggish } \\
\text { rats was not affected. } \\
\text { - A significant } \\
\text { increase in serum } \\
\text { testosterone levels in } \\
\text { subacute treatment } \\
\text { compared to control. }\end{array}$ & $\begin{array}{l}\text { EL improved the } \\
\text { copulatory } \\
\text { performance of } \\
\text { sexually sluggish } \\
\text { rats. This may } \\
\text { be attributed by } \\
\text { its ability to } \\
\text { increase serum } \\
\text { testosterone } \\
\text { level. }\end{array}$ \\
\hline
\end{tabular}


and the subacute group receiving EL dose at 500 $\mathrm{mg} / \mathrm{kg} /$ day. Rats were sacrificed $24 \mathrm{~h}$ after dosing and blood were collected for testosterone

\begin{tabular}{|c|c|c|c|c|}
\hline $\begin{array}{l}\text { Ang } \\
\text { and } \\
\text { Ngai } \\
{[34]}\end{array}$ & $\begin{array}{l}\text { In vivo } \\
\text { animal } \\
\text { study. } \\
\text { Aphrodisiac } \\
\text { evaluation. }\end{array}$ & $\begin{array}{l}\text { Non- } \\
\text { copulator } \\
\text { adult male } \\
\text { Sprague- } \\
\text { dawley rats }\end{array}$ & $\begin{array}{l}\text { Chlorofor } \\
\mathrm{m} \text {, } \\
\text { methanol, } \\
\text { water, n- } \\
\text { butanol } \\
\text { extract }\end{array}$ & $\begin{array}{l}\text { nol, } \\
\text { n- } \\
\text { l }\end{array}$ \\
\hline
\end{tabular}

$\begin{array}{lll}\text { Ang, } & \text { In vivo } & \text { Inexperience } \\ \text { Cheang } & \text { study. } & \text { d castrated } \\ \text { [31] } & \text { Initiation of } & \text { adult male } \\ & \text { sexual } & \text { Sprague- } \\ & \text { performanc } & \text { dawley rats } \\ & \text { e. }\end{array}$

Butanol, 200, 400, 800 methanol, $\mathrm{mg} / \mathrm{kg}$ (twice water, daily) for 10 chloroform d prior to the extract test, and continued throughout the test

Sexually naïve adult male

and study.

Sim Sexual

[35] motivation
$200,400,800$ $\mathrm{mg} / \mathrm{kg}$ for 12 w
Chlorofor $\mathrm{m}$, methanol, water, butanol extract

$\begin{array}{lllll}\text { Ang, } & \text { In vivo } & \text { Sexually } & \text { Butanol, } & 0.5 \mathrm{~g} / \mathrm{kg} \text { for } \\ \text { Chan } & \text { study. } & \text { naïve male } & \begin{array}{l}\text { methanol, } \\ 10 \mathrm{~d}\end{array} \\ \text { [32] } & \begin{array}{l}\text { Sexual } \\ \text { motivation }\end{array} & \begin{array}{l}\text { male albino } \\ \text { mice }\end{array} & \begin{array}{l}\text { water, } \\ \text { chloroform } \\ \text { extract }\end{array} & \end{array}$

determination.

- Sexually sluggish male rats were tested with receptive female rats for copulatory behaviour and males that failed to show any copulatory behaviour or non-copulator were selected.

- Non-copulator male rats received either EL or saline (control group).

- The measurement was made for choice selection of estrous female over male ('right', 'wrong' or 'no') and hesitation time. Rats were observed for 30 min every day for $12 \mathrm{w}$.

- Sexually inexperienced rats were castrated 60-90 $\mathrm{d}$ before testing.

- The positive control group was given testosterone

subcutaneously at 15 $\mathrm{mg} / \mathrm{kg}$ daily. Negative control group received saline. Treated groups were given EL extracts at

50-80 d post-castration.

- Sexual performance: mounts, vaginal intromissions and ejaculation.

- Growth of ventral prostate and seminal vesicles (sexual accessories)

- Sexually naïve male rats were given EL fractions or saline for the control group.

- Successful crossover, mounting, intromission and ejaculation was observed.

- 400 male mice naive to heterosexual behaviour and drugs were subjected to training protocol for 10 consecutive days. Only

240 responsive mice were selected and were divided into 12 groups.

- Selected male mice were divided into control group and 4 groups of EL extract.

- The crossover was evaluated by the modified runway-choice method.
- Non-copulator male rats receiving EL had decreased hesitation time, transient increase in percentage making the right choice with more than $50 \%$ of male rats scoring the 'right' choice.

- Effects become more prominent after $8 \mathrm{w}$ post-treatment. No enhancement was observed in control group.

- A dose-dependent increase in sexual performance with EL supplementation but lower compared to testosterone group.

- EL promoted growth of sexual accessories (at 800 $\mathrm{mg} / \mathrm{kg} \mathrm{EL}$ ) but was less than testosterone group.

- Not much

difference in sexual performance or sexual accessories growth found between various fractions of EL extracts.

- The EL groups have enhanced number of successful crossovers, mountings,

intromissions and ejaculation to the estrous receptive female

- All control male rats failed to crossover to the estrous receptive female.

- Transient increase in the percentage of male mice responding to the right choice after consumption of EL extracts.

- Enhanced sexual motivation was noticed after $3 \mathrm{~d}$ of treatment with EL extracts.

- The effect was more prominent after eight days of treatment with EL. No
EL exerted aphrodisiac effects on sexually sluggish rats. This may be attributed to the active compounds present in the EL fraction.

EL enhanced initiation of sexual performance of inexperienced castrated male rats. Therefore, EL has aphrodisiac effects.

EL enhanced copulatory behaviour. This may be attributed to the presence of active compounds in EL fractions.

EL extract has aphrodisiac qualities. Further studies are needed to determine its aphrodisiac effects in humans. 


$\begin{array}{lllll}\text { Tambi, } & \begin{array}{l}\text { Human } \\ \text { Imran }\end{array} & \begin{array}{l}\text { Hypogonadic } \\ \text { study. Late- } \\ \text { onset }\end{array} & \begin{array}{l}\text { Standardis } \\ \text { males }\end{array} & \begin{array}{l}200 \mathrm{mg} \text { daily } \\ \text { soluble }\end{array} \\ \text { hypor } 1 \mathrm{mo}\end{array}$

sm
Another similar six groups were evaluated using modified open field method.

- 320 patients opted for hypogonadism and LOH treatment were identified using AMS and testosterone level $(<6$ $\mathrm{nmol} / \mathrm{l}$ ). Patients were treated with two capsules of $100 \mathrm{mg}$ daily for $1 \mathrm{mo}$. - AMS score and serum testosterone concentration were reported for only 76 subjects with $\mathrm{LOH}$ and had completed a full course of EL supplementation. enhancement of

sexual motivation was

noticed in control

group.

- EL significantly

( $\mathrm{p}<0.0001)$ improved

the AMS score and serum testosterone concentration. After treatment completion, $71.7 \%$ patients showed normal values of AMS score and $90.8 \%$ showed normal testosterone level.

- AMS score includes the ability/frequency to perform sexual activity, number of morning erections and sexual desire/libido.
The results indicated that EL supplementatio $\mathrm{n}$ is useful for overcoming symptoms of $\mathrm{LOH}$ and management of hypogonadism.

\section{Effects of EL on sexual behaviour in animal study}

A total of five animal studies were included for the evaluation of EL effects on sexual behaviours in the sexually dysfunctional male. Ang and Sim [35] treated sexually naïve male rats with various fractions of EL at 200,400 and $800 \mathrm{mg} / \mathrm{kg}$ for 12 consecutive weeks. Copulatory behavior test showed that repeated and chronic dosing of EL enhanced and maintained high levels of successful crossovers, mountings, intromissions and ejaculations during the 9 to $12^{\text {th }}$ week observation period. All the control male rats failed to crossover to estrous receptive female. In the study by Ang, Cheang [31], administration of 200,400 and $800 \mathrm{mg} / \mathrm{kg}$ of EL to inexperienced castrated male rats produced a dose-dependent increase in sexual performance. However, the improvement in sexual performance was not as high as the testosterone or positive control group.

In another study, acute (500 and $1000 \mathrm{mg} / \mathrm{kg}$ ) and subacute $(500$ $\mathrm{mg} / \mathrm{kg}$ ) treatment of EL extracts to sexually sluggish male rats was shown to reduce ejaculation latencies and increase the percentage of mounting and ejaculation [33]. The reduced post-ejaculatory interval was also found with subacute EL administration. Meanwhile, subacute and subchronic treatment of EL was shown to increase the percentage of mounting and ejaculation in impotent rats. Based on the partner preference test, there was no preferred selection towards estrous female overactive male. Therefore, the motivational behaviour of the sluggish rats was not influenced by EL treatments. Testosterone levels were found to be increase in rats when subacutely treated with EL compared to control.

Ang, Chan [32] treated sexually naïve male mice with $0.5 \mathrm{~g} / \mathrm{kg}$ of various fractions of EL and sexual motivation were evaluated daily for 10 consecutive days by measuring the percentage of male mice responding to right (estrous female), wrong (active male) or no choice. Sexual motivation was enhanced after three days of EL treatment and the effect was more prominent after eight days posttreatment in which more than $65 \%$ of the male mice scored the right choice. In the study by Ang and Ngai [34], daily administration of various EL extracts at $0.5 \mathrm{~g} / \mathrm{kg}$ for 12 consecutive weeks was shown to decrease hesitation time of the sexually sluggish male rats. There was a transient increase in the percentage of the male rats responding to the right choice and the effect became more prominent after $8 \mathrm{w}$ of treatment.

\section{Effects of EL on sexual behaviour in human study}

In a study by Tambi, Imran [25], 76 subjects from 320 patients with the symptoms of hypogonadism and $\mathrm{LOH}$ had completed a full course of EL supplementation (200 mg) for $1 \mathrm{mo}$ and came for a regular follow-up examination. The Ageing Males' Symptoms (AMS) score was used to categorize patients from 'no complaints' to 'severe complaints', while the serum testosterone concentrations was categorized into normal $(6-30 \mathrm{nmol} / \mathrm{l})$ and low $(<5.99 \mathrm{nmol} / \mathrm{l})$.

Results indicated significant correlations between the patients' age, the AMS score and testosterone concentration before and after treatment with EL. Before the start of treatment, only $10.5 \%$ of the patients were in the 'no complaints' category of the AMS scale and $35.5 \%$ had normal testosterone level. Upon completion of treatment, $71.7 \%$ and $90.8 \%$ of the patients showed the 'no complaints' AMS category and normal testosterone level, respectively. The author suggested that EL extract is useful to be taken as a supplement to overcome the symptoms of $\mathrm{LOH}$ and for hypogonadism management.

\section{DISCUSSION}

This review has revealed the beneficial findings of EL extract in enhancing sexual behaviour in an animal model and human study. This review focused on the possible therapeutic effect of EL in sexual dysfunctions using castrated, non-copulator, sexually naïve, and sexually sluggish or impotent animal models. Subjects in the human study were patients suffering from late-onset hypogonadism. The results scientifically substantiate the traditional claims that the root of EL has the male sexual enhancing ability.

Rats were used as subjects of sexual behaviour studies because they share similar homologies with human copulatory behaviour including the mechanism of penile erection [36]. Ang and Sim [35] have investigated the effects of EL on copulatory behaviour in sexually naïve male rats that have no prior copulation experience. The results have shown that the root extract of EL enhanced and maintained sexual parameters in rats' sexual behaviour when compared to the control animals. Successful crossover, mounting, intromission and ejaculation were enhanced in a time-dependent manner, indicating the stimulation of sexual arousability, performance, motivation and vigour in the rats. Ang, Cheang [31] demonstrated that supplementation of EL produced a dosedependent increase in sexual performance in inexperienced castrated rats. The authors suggested that EL enhanced the initiation of sexual performance of inexperienced castrated male rats. However, the sexual performance produced was less than that of the testosterone-treated animal. In this study, a decrease in sexual behaviour was due to complete absence of testosterone in castrated rat model. The supplementation of EL extract may have raised the testosterone level, thus enhancing the sexual performance.

With regards to sexual motivation, there were two animal studies that evaluated the choice of the selection made by the noncopulatory and sexually naïve animals. The right choice would be estrous female rats, while the wrong choice would be active male rats. Ang, Chan [32] found that sexual motivation of sexually naïve 
male mice was enhanced with EL supplementation as indicated by the increase in the percentage of male mice responding to the right choice. Similar findings were obtained by Ang and Ngai [34], which has shown that the percentage of sexually sluggish male rats responding to the right choice was increased. This enhancement of sexual motivation in the tested animals was more prominent after chronic administration of EL extract. Other than that, the results showed that EL extract decreased the hesitation time of noncopulator rats compared to control rats. The result is indicative of enhanced sexual appetitive behaviour as these parameters were considered to be associated to sexual motivation or desire [37].

The evaluation of sexual behaviour in sexually sluggish and impotent rats closely described the age-related and disease-related sexual dysfunctions [38]. Zanoli, Zavatti [33] have investigated the effect of acute and subacute administration of EL in sexually sluggish and impotent male rats. Ejaculation latencies and post-ejaculatory interval were decreased while the percentage of mounting and ejaculating was increased with EL supplementation in sexually sluggish rats. The percentage of mounting and ejaculating were also increased by subacute and subchronic supplementation of EL to impotent rats. In general, the reduction of ejaculation latency and the post-ejaculatory interval is indicative of an improvement in copulatory behaviour, particularly when observed together with an increase in mounting and ejaculating animals. The results showed that oral administrations of EL extract might be beneficial to manage arousal and ejaculation disorders in males. In parallel with the improvement of copulatory activity, subacute EL extract supplementation was found to be able to increase testosterone level. Several aphrodisiac plants were also shown to have a testosteroneenhancing effect (e. g. Tribulus terrestris, Panax ginseng, Bulbine natelensis), thus improving sexual function [38-40]. An aphrodisiac that works well centrally and peripherally can be clinically well accepted since the sexual response is the results of neuronal (both central and peripheral), hormonal and peripheral activities [41]. Testosterone may be involved in facilitating male sexual behaviour by increasing dopamine release in the medial preoptic area and potentiating nitrergic neurotransmission [42].

The aphrodisiac property of EL was demonstrated in a human study involving $\mathrm{LOH}$ patients. Limitation of the human study was the survey did not provide information about individual behaviour, practices, and attitudes regarding sexuality. Due to the sensitive nature of the topic, the survey might be difficult to be carried out. A survey on sexual attitudes and behaviour showed an association between sexual problems with depression and aging in men [10]. Tambi, Imran [25] demonstrated that EL significantly normalized the testosterone level and improved the AMS. Psychological and sexual factors are the two important factors in AMS in which the sexual factor comprises of potency, erectility and libido. This was the first study that aimed at investigating the effects of EL extracts in patients suffering from $\mathrm{LOH}$ and confirming the testosterone stimulating properties of the standardized water-soluble extract of EL. Hypogonadism may leads to decrease sexual interest, quality of erections and quality of life [43]. Findings of this study supported the traditional claim that the herbal extract of EL has the potential to treat sexual dysfunction including erectile dysfunction by increasing the testosterone level to normal values.

Recent evidence suggests that based on the study in the moderately stressed subject, standardized hot-water extract of EL could restore cortisol/testosterone hormone balance and improve psychological mood state [44]. Hence, EL may have the potential to reduce the risk of sexual problems due to psychological changes in humans exposed to various modern stressors including aging. The improvements in testosterone level may lead to the enhancement in sexual activities and well-being. Furthermore, the ability of EL to elevate testosterone level without affecting liver function (in terms of ALT and AST) suggests that it may also be useful in improving sexual function in men with any cases of sexual debility [44]. In a recent randomized clinical study, supplementation of freeze-dried water extract of EL (300 mg/day) significantly improved overall erectile function domain, sexual libido, sexual performance and satisfaction with a marginal increase in the testosterone level by the end of $12 \mathrm{w}$ treatment [24].
Although the mechanism of the effect of EL on the sexual qualities remains unknown, the enhancement in sexual behaviour may be attributed by an increase in testosterone level. The eurypeptides complex that is contained in EL was thought to be responsible for the reported effects. It works by activating the CYP17 enzyme (17 ahydroxylase $/ 17,20$ lyase) to enhance the biosysthesis of various androgens [45]. This is also supported by laboratory evidence that shows eurycoma peptides could stimulate the release of free testosterone from its binding proteins and improve overall hormone profiles [44]. Androgen, particularly testosterone was suggested to be involved in the complex mechanism that regulated the copulatory behaviour and contributed to the improvement in sexual function, libido and penile erection $[39,46]$. Therefore, the mechanism of action of this plant could be ascribed to a hormonal influence in enhancing male copulatory behaviour.

\section{Strength and limitation}

Studies on the effects of EL on sexual behaviour in sexually dysfunctional male have shown some promising results in terms of copulatory parameters and hormonal balance. In the pursuit of seeking safe therapeutic alternative treatments to current modalities for the management of sexual dysfunction in males, a critical review is highly relevant. This systematic review identified 6 research articles and to the best of our knowledge; this is the first critical review that focuses on the effects of EL on sexual behaviour in sexually dysfunctional male, which included animal and human studies. The evaluation for aphrodisiac and sexual enhancing activity of EL in sexually dysfunctional male instead of the healthy/normal subject is thought to be a better predictor for their reported efficacy.

Several limitations such as inadequate details in the publications and protocol violations were identified for this review. Data on the individual behaviour, practices and attitudes regarding sexuality, pre-and post-supplementation with EL in the human studies were not available. Majority of the studies particularly the animal studies did not clearly describe the underlying mechanism of action, pharmacokinetic and pharmacodynamic profiles of EL in enhancing the sexual behaviour in the sexually dysfunctional male.

\section{Recommendation}

More studies are required to identify the exact EL active ingredients and the molecular mechanisms involved in male sexual dysfunctions. It can probably be explored for the management of arousal/desire disorders, erectile dysfunction, premature ejaculation and hypogonadism in man by doing further studies. Future research should also emphasize the pharmacokinetic and pharmacodynamic profiles of EL.

\section{CONCLUSION}

EL extract has shown good outcomes on the sexual behaviour of male sexual dysfunction but data from well-designed human studies are still lacking. Findings of this review further supported the use of this plant for its aphrodisiac property. More studies are required to determine the active ingredients and the molecular mechanisms that are responsible for its reported effects.

\section{ACKNOWLEDGEMENT}

We would like to thank the Faculty of Medicine Universiti Kebangsaan Malaysia for providing resources to write this systematic review.

\section{CONFLICT OF INTERESTS}

The author (s) confirm that this review article content has no conflict of interest.

\section{REFERENCES}

1. Guay AT, Spark RF, Bansal S, Cunningham Gr, Goodman NF, Nankin HR, et al. American association of clinical endocrinologists medical guidelines for clinical practice for the evaluation and treatment of male sexual dysfunction: a couple's problem--2003 update. Endocr Pract 2003;9:77-95.

2. Lewis RW, Fugl-Meyer KS, Bosch R, Fugl-Meyer AR, Laumann EO, Lizza E, et al. Epidemiology/risk factors of sexual dysfunction. J Sex Med 2004;1:35-9. 
3. Patel DK, Kumar R, Prasad SK, Hemalatha S. Pharmacologically screened aphrodisiac plant-A review of the current scientific literature. Asian Pac J Trop Biomed 2011;1:S131-8.

4. Hatzimouratidis K, Amar E, Eardley I, Giuliano F, Hatzichristou D, Montorsi $\mathrm{F}$, et al. Guidelines on male sexual dysfunction: erectile dysfunction and premature ejaculation. Eur Urol 2010;57:804-14.

5. Lue TF. Erectile dysfunction. N Engl J Med 2000;342:1802-13.

6. Braun M, Wassmer G, Klotz T, Reifenrath B, Mathers M, Engelmann U. Epidemiology of erectile dysfunction: results of the' Cologne Male Survey'. Int J Impotence Res 2000;12:305-11.

7. Feldman HA, Goldstein I, Hatzichristou DG, Krane RJ, McKinlay JB. Impotence and its medical and psychosocial correlates: results of the Massachusetts Male Aging Study. J Urol 1994;151:54-61.

8. Kotta S, Ansari SH, Ali J. Exploring scientifically proven herbal aphrodisiacs. Pharmacogn Rev 2013;7:1-10.

9. McMahon CG, Abdo C, Incrocci L, Perelman M, Rowland D, Waldinger $\mathrm{M}$, et al. Disorders of orgasm and ejaculation in men. J Sex Med 2004;1:58-65.

10. Laumann EO, Nicolosi A, Glasser DB, Paik A, Gingell C, Moreira $\mathrm{E}$, et al. Sexual problems among women and men aged 40-80 y: prevalence and correlates identified in the Global Study of Sexual Attitudes and Behaviors. Int J Impot Res 2005;17:39-57.

11. Corona G, Petrone L, Mannucci E, Jannini EA, Mansani R, Magini $A$, et al. Psycho-biological correlates of rapid ejaculation in patients attending an andrologic unit for sexual dysfunctions. Eur Urol 2004;46:615-22.

12. Chia SJ. Management of premature ejaculation-a comparison of treatment outcome in patients with and without erectile dysfunction. Int J Androl 2002;25:301-5.

13. Mulhall JP, Hsiao W. editors. Men's Sexual Health and Fertility: A Clinician's Guide. New York: Springer; 2014.

14. Low WY, Wong YL, Tan HM. Malaysian cultural differences in knowledge, attitudes and practices related to erectile dysfunction: focus group discussions. Int J Impot Res 2002;14:440-5.

15. Laumann EO, A Paik, RC Rosen. Sexual dysfunction in the United States: prevalence and predictors. JAMA 1999;281:537-44.

16. Boolell M, Gepi-Attee S, Gingell JC, Allen MJ. Sildenafil, a novel effective oral therapy for male erectile dysfunction. Br J Urol 1996;78:257-61.

17. Patnaik SK, Haritha P, Rajeswara RP. Erectile dysfunction and its pharmacology: an overview. Asian J Pharm Clin Res 2017;10:17-23.

18. Tan HM, Low WY, Ng CJ, Chen KK, Susita M, Ishii N, et al. Prevalence and correlates of erectile dysfunction (ED) and treatment seeking for ED in Asian men: the Asian Men's Attitudes to Life Events and Sexuality (MALES) study. J Sex Med 2007;4:1582-92.

19. Rhoden EL, Morgentaler A. Risks of testosterone-replacement therapy and recommendations for monitoring. N Engl J Med 2004;350:482-92.

20. Gooren LJ, Behre HM, Saad F, Frank A, Schwerdt S. Diagnosing and treating testosterone deficiency in different parts of the world. Results from global market research. Aging Male 2007;10:173-81.

21. Adimoelja A. Phytochemicals and the breakthrough of traditional herbs in the management of sexual dysfunctions. Int J Androl 2000;23:82-4.

22. Yakubu MT, Akanji MA, Oladiji AT. Male sexual dysfunction and methods used in assessing medicinal plants with aphrodisiac potentials. Pharmacogn Rev 2007;1:49-56.

23. Carro-Juarez M, Lobaton I, Benitez O, Espiritu A. Proejaculatory effect of the aqueous crude extract of cihuapatli (Montanoa tomentosa) in spinal male rats. J Enthnopharmacol 2006;106:111-6.

24. Ismail SB, Wan Mohammad WMZ, George A, Nik Hussain NH, Kamal ZMM, Liske E. Randomized clinical trial on the use of PHYSTA freeze-dried water extract of Eurycoma longifolia for the improvement of the quality of life and sexual well-being in men. J Evidence-Based Complementary Altern Med 2012;1-0. http://dx.doi.org/10.1155/2012/429268.
25. Tambi M, Imran M, Henkel R. Standardised water-soluble extract of Eurycoma longifolia, Tongkat ali, as testosterone booster for managing men with late-onset hypogonadism? Andrologia 2012;44:226-30.

26. George A, Henkel R. Phytoandrogenic properties of Eurycoma longifolia as a natural alternative to testosterone replacement therapy. Andrologia 2014;46:708-21.

27. Sreedevi P, Vijayalakshmi K, Venkateswari R. Evaluation of Punica granatum L. leaf extract. Int J Curr Pharm Res 2017;9:14-8.

28. Bhat R, Karim A. Tongkat ali (Eurycoma longifolia Jack): a review on its ethnobotany and pharmacological importance. Fitoterapia 2010;81:669-79.

29. Malaysian Standards. Phytopharmaceutical aspects of freeze dried water extract from tongkat ali roots-specification. Department Standards Malaysia 2011;MS:2409.

30. Sambandan TG, Rha CK, Kadir AA, Aminudim N, Saad JM. Inventors; Government of Malaysia, Massachusetts Insitute of Technology, assignee. The bioactive fraction of Eurycoma longifolia. US7132117B2; 2006.

31. Ang HH, Cheang HS, Yusof APM. Effects of Eurycoma longifolia Jack (Tongkat Ali) on the initiation of sexual performance of inexperienced castrated male rats. Exp Anim 2000;49:35-8.

32. Ang HH, Chan KL, Gan EK, Yuen KH. Enhancement of sexual motivation in sexually naive male mice by Eurycoma longifolia. Int J Pharmacogn 1997;35:144-6.

33. Zanoli P, Zavatti M, Montanari C, Baraldi M. Influence of Eurycoma longifolia on the copulatory activity of sexually sluggish and impotent male rats. J Ethnopharmacol 2009;126:308-13.

34. Ang H, Ngai T. Aphrodisiac evaluation in non-copulator male rats after chronic administration of Eurycoma longifolia Jack. Fundam Clin Pharmacol 2001;15:265-8.

35. Ang HH, Sim MK. Eurycoma longifolia increases sexual motivation in sexually naive male rats. Arch Pharm Res 1998;21:779-81.

36. Pfaus JG, Frank A. Beach award: homologies of animal and human sexual behaviors. Horm Behav 1996;30:187-200.

37. Yakubu MT, Akanji MA, Oladiji AT. Aphrodisiac potentials of the aqueous extract of Fadogia agrestis (Schweinf. Ex Hiern) stem in male albino rats. Asian J Androl 2005;7:399-404.

38. Singh S, Nair V, Gupta YK. Evaluation of the aphrodisiac activity of Tribulus terrestris Linn. in sexually sluggish male albino rats. J Pharmacol Pharmacother 2012;3:43-7.

39. Gauthaman K, Adaikan PG, Prasad RNV. Aphrodisiac properties of Tribulus Terrestris extract (Protodioscin) in normal and castrated rats. Life Sci 2002;71:1385-96.

40. Yakubu M, Afolayan A. Effect of aqueous extract of Bulbine natalensis (Baker) stem on the sexual behaviour of male rats. Int J Androl 2009;32:629-36.

41. Shekar S, Vazir M, Kempanna B, Miryala SK, Subedi A. Effect of yohimbine on clomipramine-induced sexual dysfunction in male rats. Asian J Pharm Clin Res 2017;10:92-6.

42. Putnam SK, Du J, Sato S, Hull EM. Testosterone restoration of copulatory behavior correlates with medial preoptic dopamine release in castrated male rats. Horm Behav 2001;39:216-24.

43. Morales A, Buvat J, Gooren LJ, Guay AT, Kaufman JM, Tan HM, et al. Endocrine aspects of sexual dysfunction in men. J Sex Med 2004;1:69-81.

44. Talbott SM, Talbott JA, George A, Pugh M. Effect of tongkat ali on stress hormones and psychological mood state in moderately stressed subjects. J Int Soc Sport Nutr 2013;10:28.

45. Ali J, Saad J. Biochemical effect of Eurycoma longifolia Jack on the sexual behaviour, fertility, sex hormone and glycolysis [Dissertation]. Department of Biochemistry: University of Malaya; 1993.

46. Aversa A, Fabbri A. New oral agents for erectile dysfunction: what is changing in our practice. Asian J Androl 2001;3:175-9. 